\title{
Influence of Breathing and Chewing on Timing of Flavor Detection
}

\author{
Satomi Miyaoka1, Yozo Miyaoka ${ }^{2 *}$ \\ ${ }^{1}$ Department of Eating Disorder and Dysphagia, Graduate School of Rehabilitation, Niigata University of Rehabilitation, \\ Murakami, Japan \\ ${ }^{2}$ Department of Health and Nutrition, Niigata University of Health and Welfare, Niigata, Japan \\ Email: ^miyaoka@nuhw.ac.jp
}

How to cite this paper: Miyaoka, S. and Miyaoka, Y. (2017) Influence of Breathing and Chewing on Timing of Flavor Detection. Journal of Behavioral and Brain Science, 7, 1-8.

http://dx.doi.org/10.4236/jbbs.2017.71001

Received: December 13, 2016

Accepted: January 8, 2017

Published: January 11, 2017

Copyright (c) 2017 by authors and Scientific Research Publishing Inc. This work is licensed under the Creative Commons Attribution International License (CC BY 4.0).

http://creativecommons.org/licenses/by/4.0/

\section{(c) (†) Open Access}

\begin{abstract}
This study aimed to analyze frequencies of flavor detection signals occurring in any of the three respiratory phases and either of the two masticatory phases. Flavors of three fruity (grape, orange, and strawberry) gummy candies in the mouth were detected after chewing in 24 young healthy participants. The results revealed that: 1) more detection signals occurred in the expiratory phase than in the inspiratory or pausing phases and 2) more detection signals occurred in the jaw-closing phase than in the jaw-opening phase. Statistical analysis showed that the difference between the frequencies among the three respiratory phases was significant $(P<0.001)$ but not between the two masticatory phases. Further analysis showed that the frequencies occurring within individual respiratory phases were not significantly biased. The present results suggest that flavor detection during chewing depends more on the expiratory phase rather than the inspiratory and pausing phases, whereas detection is dependent to a lesser extent on either of the masticatory phases.
\end{abstract}

\section{Keywords}

Respiratory Phase, Masticatory Phase, Flavor Detection

\section{Introduction}

There are two routes for flavor perception [1] [2]: inhalation of flavored vapors is responsible for orthonasal perception, whereas exhalation is responsible for retronasal perception. The olfactory receptors are stimulated by vapors through the nostrils in the orthonasal route and through the nasopharynx in the retronasal route. Consequently, during natural breathing, the inspiratory and expiratory airflows serve for the orthonasal and retronasal flavor perceptions, respectively. The airflows play two important roles (mechanical and neural) in flavor 
perception. First, the airflows transport flavored vapors mechanically to the olfactory receptors. Second, the airflows provide sensory neural signals that drive and synchronize the activity of the entire olfactory system [3] [4].

A previous study showed that the perceived magnitude of odorants with chewing-like movement under the open nostrils was stronger than that without this movement [5]. This result suggests that not only respiratory movement but also masticatory movement affects retronasal perception. However, no studies have more precisely analyzed the effects at the phase level [6]. Therefore, this study examined the phasal relations between flavor detection during chewing of flavored foods and respiratory and masticatory movements by testing whether flavor detection 1) depends on respiratory phases; 2) occurs at any specific times during the respiratory phases; and 3) depends on either of the masticatory phases.

\section{Materials and Methods}

\subsection{Participants}

For this study, 24 young, healthy adults ( $20.2 \pm 1.3$ yrs old) were included. They were assigned to the Experimental (Exptl) group ( $\mathrm{n}=24 ; 9$ men and 15 women), and 11 of them were also randomly assigned to the Control (Cont) group ( 3 men and 8 women). The participants were paid and recruited from undergraduate students of Niigata University of Rehabilitation. In the recruitment, the students who reported any subjective problems in sensory (especially, olfactory and taste) and motor functions were excluded. The Cont group was recruited to check whether the action of pressing a signal button (see "Procedures") itself affects breathing and/or chewing or vice versa. The experiments were conducted for two months. Informed consent was obtained from all participants. The experiments were approved by the Ethics Committee of The University of Niigata Rehabilitation Graduate School.

\subsection{Test Foods}

Since our preceding study indicated differential effects of flavors on detection time (Miyaoka, et al. 2014), three fruity (grape, orange, and strawberry) gummy candies (Meiji Co., Ltd., Tokyo, Japan) were used as test foods to check whether different flavors affect respiratory and/or masticatory phases. The approximate height, width and thickness of the gummy candies were $9.5 \mathrm{~mm} \times 23.6 \mathrm{~mm} \times$ $15.0 \mathrm{~mm}$. Each test food was wrapped with a wafer paper (Kokko Oblaat Co., Ltd., Shizuoka, Japan) to prevent direct contact between the food and oral tissues before onset of chewing.

\subsection{Procedure}

The outlines of the procedures adopted were the same as the methods reported in previous papers [7] [8]. Each participant was asked to rinse his or her mouth with water and sit comfortably in a chair. A thermistor (EPU356; AD Instruments Pty Ltd., Bella Vista, Australia) was attached to every seated participant's 
nostril to monitor breathing. A pair of electrodes (Ambu Inc., Blue Sensor, Maryland, USA) was attached to the skin just above the masseter (Mass) muscle to record a surface electromyogram (EMG), as an index for chewing. The Mass EMG was recorded from the habitual chewing side of each participant determined by personal statement. Mass EMG signals were amplified, filtered, fully rectified, and stored on a digital recorder (Power Lab system; AD Instruments Pty Ltd., Power Lab/8 sp, Bella Vista, Australia). Each participant held a button connected to a recorder in his or her dominant hand.

The participant was then asked to rinse his or her mouth with water. A test food was randomly provided to the participant and he or she was asked to hold it between their molars until the delivery of the command to begin chewing, whereas, the participant was not required to close his or her mouth during chewing. After the delivery of the command, the participant started chewing at will. The Exptl group participants were asked to immediately press the recording button when they detected any flavor of test food on being asked to chew, whereas, the Cont group participants were asked to press the button any time they wanted to. A pulse signal was generated by pressing the recording button for flavor detection or for voluntary pressing and the signal was conveyed to the digital recorder. Prior to delivery, the flavor of the test foods was given to every participant of each group.

\subsection{Data and Statistical Analyses}

First, the number of detection signals for both groups were counted; the signals occurred for any of the three respiratory phases, namely, inspiratory (Insp), expiratory (Exp) and pausing (Paus). They were determined by thermal changes associated with breathing recorded with the nose thermistor [9], or one of the two masticatory phases, namely, jaw-opening (JO) and jaw-closing (JC), which were determined in turn by the activity of the Mass EMG [10]. The three respiratory phases were determined by the curve recorded with the thermistor on the nostril (see Figure 1); 1) the period of the temperature fall was defined as the Insp phase; 2) the period of the temperature rise was defined as the Exp phase; and 3) the period of the temperature remaining stable was defined as the Paus phase. The two masticatory phases were determined by the Mass EMG record; the period of the EMG fired was defined as the JC phase, whereas the period of the EMG silent was defined as the JO phase. Second, the signals' relative location during the three respiratory phases when the participants signaled was measured. The relative location in the respiratory phases was calculated using the following equation, producing a percentage figure:

Time difference of signaling from the beginning of the respiratory phase/Duration of respiratory phase $\times 100$.

Four statistical examinations were used in this study: 1) A chi-square $\left(\chi^{2}\right)$ test for the association between categorical variables (respiratory and masticatory phases; goodness of fit test); 2) the Bartlett test for testing the homogeneity of sample distributions; 3 ) the Kruscal-Wallis test for the comparison of two means 

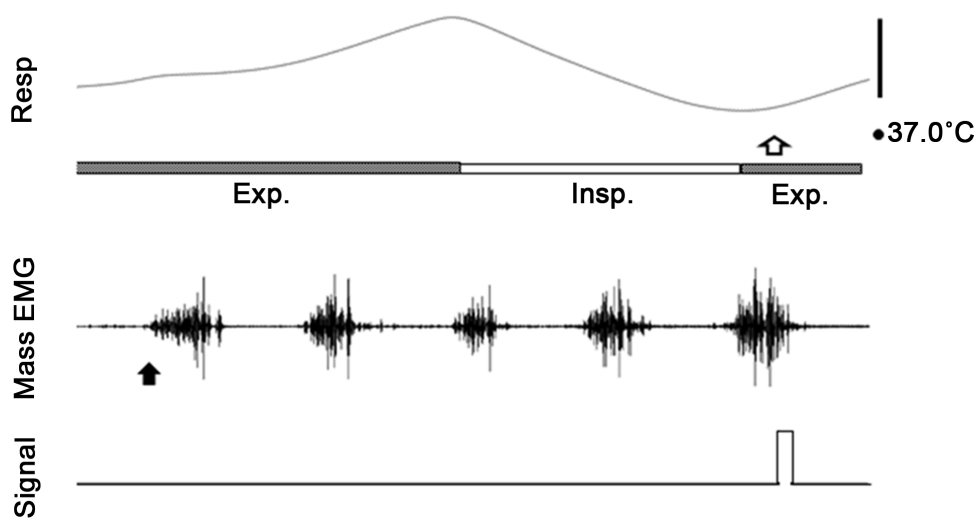

(a)
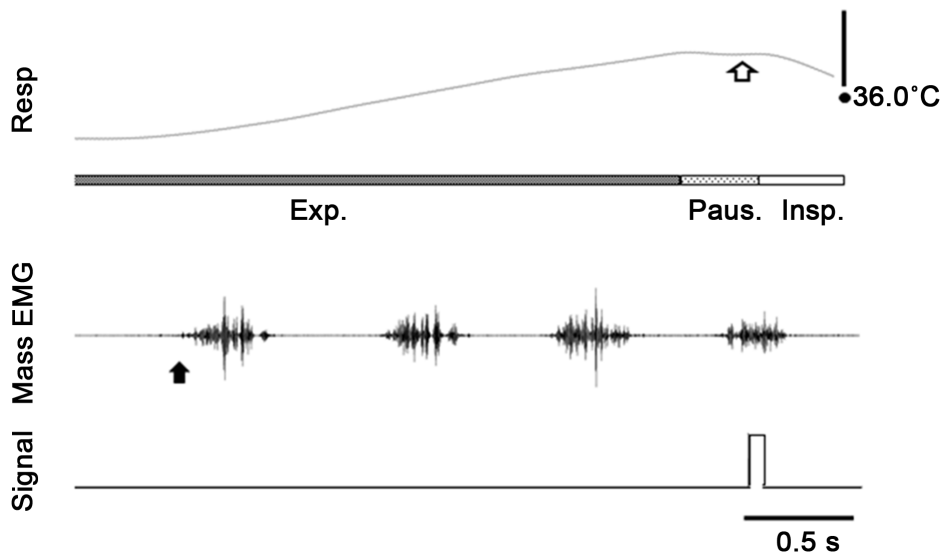

(b)

Figure 1. Sample data collected in the experimental group in a participant. (a): grape; (b): strawberry-flavored gummy candies. Resp: respiration curve (upwards, expiration), Mass EMG: a masseter surface electromyogram, Signal: time of signaling. Dots on the left show $37.0^{\circ} \mathrm{C}(\mathrm{a})$ and $36.0^{\circ} \mathrm{C}(\mathrm{b})$, and vertical bars on the right indicate $0.1^{\circ} \mathrm{C}$. Closed arrows on the left side indicate the start of chewing shown by the masseter muscle activity, and open arrows on the right side indicate the time of flavor detection. Flavor detection time was measured from the start of chewing.

(ANOVA) and t-test for the comparison of two means with parametric sample distributions. In all examinations, $P<0.05$ was considered to be statistically significant.

\section{Results}

Figure 1 depicts sample data collected in the Exptl group; a flavor detection signal was observed either in the Exp (Figure 1(a)) or Paus phase (Figure 1(b)) for each participant. Many more signals occurred in the Exp phase $(n=47)$ than in the Insp $(\mathrm{n}=20)$ and Paus phases $\left(\mathrm{n}=8\right.$, Figure $2(\mathrm{a}) ; \chi^{2}$ test, $\left.P<0.001\right)$, although no significant differences in the average time were observed among the three respiratory phases (Figure 2(b); Kruscal-Wallis test): the averages were $1.23 \mathrm{sec}$ (for the inspiratory phase), $1.41 \mathrm{sec}$ (for the expiratory phase) and 0.80 sec (for the pausing phase). The $\chi^{2}$ test showed no significant differences in signals observed in the Insp and Exp phases among the three respiratory phases. 


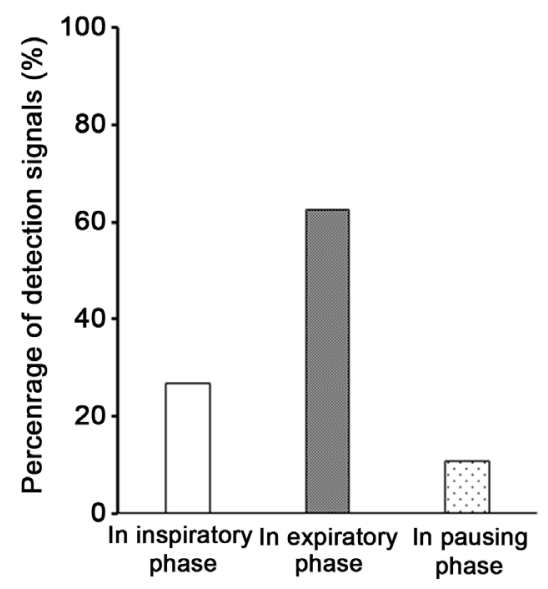

(a)

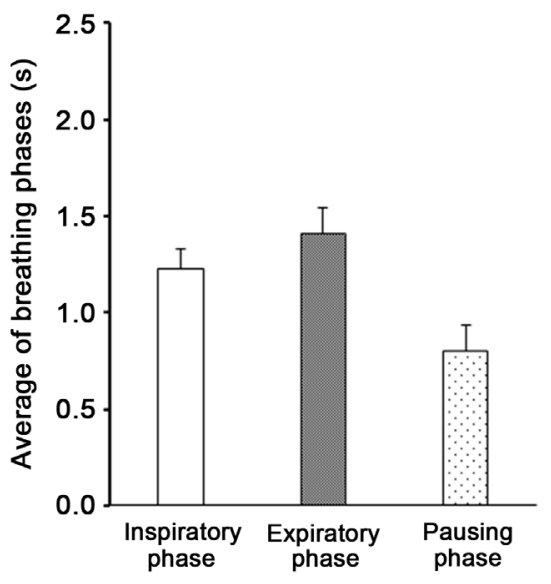

(b)

Figure 2. Comparison of the number of signals occurred and average time of three respiratory phases. Percentages (a) and average time (+SEM; (b)) of the three respiratory phases in which flavor detection signals occurred.

In contrast, the Cont group did not demonstrate such a difference in the three phases. The signals' relative location was unequally distributed across the three phases but none indicated significant differences in proportion (Figure 3(a)-(c); $\chi^{2}$ test).

Two detection signals in Figure 1(a) and Figure 1(b) were observed during the JC phase. In fact, more signals were seen during the JC phase $(\mathrm{n}=74)$ than the JO phase ( $n=73$; Figure $4(\mathrm{a})$ ). Furthermore, the average time of the JC phase $(0.54 \mathrm{~s})$ was significantly shorter than that of the JO phase $(0.45 \mathrm{~s}$; Figure 4(b); t-test, $P<0.005)$. However, no significant differences were seen between the two proportions.

\section{Discussion}

The first finding of this study, namely that flavor detection during chewing is more frequently observed in the Exp phase than in the Insp or the Paus phase (Figure 2(a)), is consistent with previous studies [11] [12]. In one study [11], participants had to estimate the perceived magnitude of a taste stimulus alone (saccharin) and a mixture of the taste stimulus with an odor stimulus (ethyl butyrate) in two conditions (nostrils open and closed). The perceived taste magnitude of the mixture was larger than that for the taste stimulus alone, only when nostrils were open. In another study [12], participants compared with the perceived magnitude of an odor stimulus alone (citral), presented in the mouth between open and closed nostrils. The perceived magnitude increased by raising the concentration of the stimulus only when nostrils were open. These previous studies suggest a critical role played by airflow through the nostrils in perceiving flavor/odor from stimuli in the mouth. The airflow corresponds to expiratory airflow during natural breathing, that is, retronasal perception of flavor/odor. The present study did not require participants to close their mouth during chewing; however, most participants did so naturally. Thus, the possibility is probably low that the flavor of the test food chewed leaked out from the mouth 


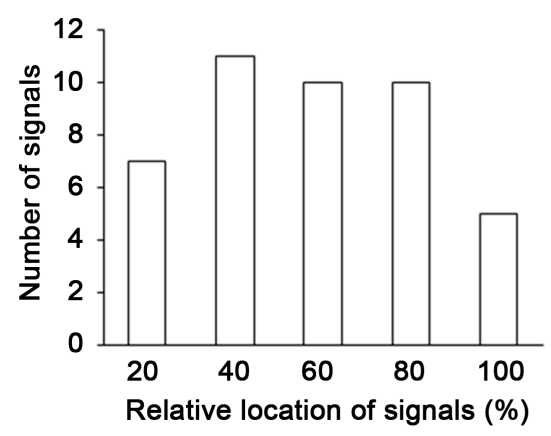

(a)

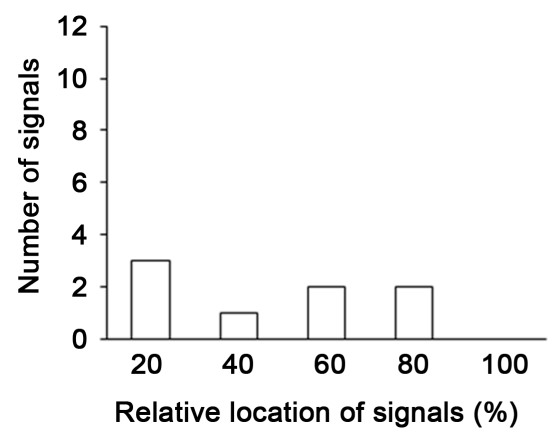

(c)

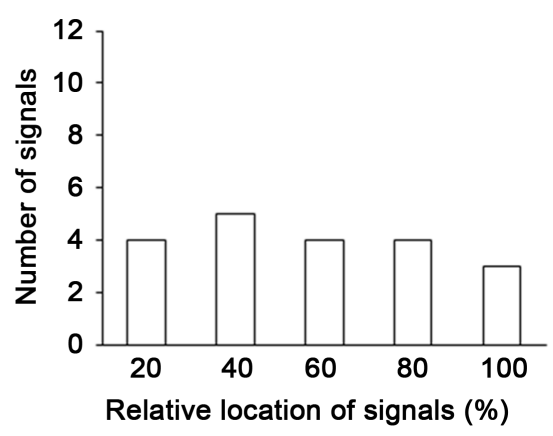

(b)

Figure 3. Frequency distributions of flavor detection signals in three respiratory phases. The numbers of signals occurred in the expiratory (a), inspiratory (b) and pausing (c) phases. See the text for the calculation of the relative location in the respiratory phases ("Data and Statistical Analyses" in the "Method" section).

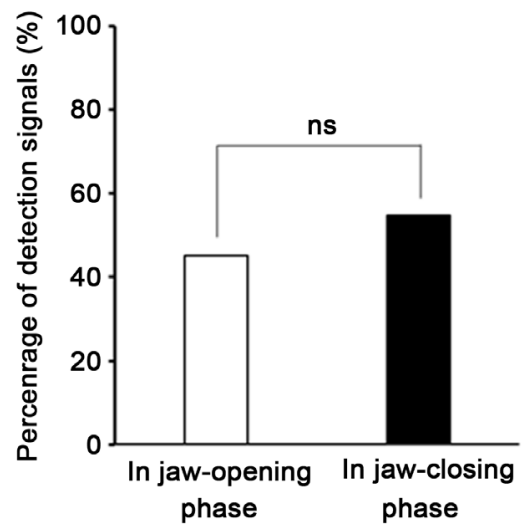

(a)

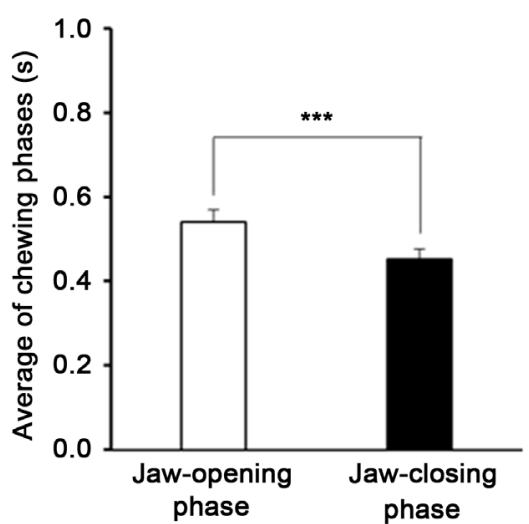

(b)

Figure 4. Comparison of the number of signals occurred and average time of two masticatory phases. Percentages (a) and average time (+SEM; (b)) of the two masticatory phases where inflavor detection signals occurred. Ns: not significant, ${ }^{* * *} P<0.001$.

that the flavor of the test food chewed leaked out from the mouth and stimulated the nose. Although it is difficult for us to explain the result that nearly $30 \%$ of detection signals occur in the inspiratory phase (Figure 2(a)), the following situation in our experiments may be related to the result; i.e., fruity flavors in the test foods used are not detected just after the participants begin chewing. Instead, they are detected after a relatively long time, around $4 \mathrm{~s}$ [7] [8]. The long 
detection time could allow a sufficient diffusion of flavors to the whole nasal cavity, resulting in detection becoming independent of the respiratory phases.

Statistical analyses showed that the relative locations of detection signals were not biased in any of the respiratory phases (Figures 3(a)-(c)); however, a temporal factor needed to be considered in the interpretation of the results. That is, time lag between flavor detection in the brain and time of signaling by the hand might have affected the determination of the respiratory phase wherein detection signals occurred. A recent study reports that transcranial magnetic stimulation of the motor area can evoke potentials in the flexor hallucis brevis and that the average latency period for evoked potentials is less than $40 \mathrm{msec}$ [13]. In this study, the average latency was $1.2 \%$ of the average time of the average respiratory cycle, including the pausing phase (Figure $2(\mathrm{~b})$ ). This would have presumably played a minor or negligible role in the determination for the following reason. There were no statistically significant differences in the average time among the three respiratory phases (Figure 2(b)). Therefore, the three percentages of detection signals that occurred in the individual respiratory phases could only have shifted as a whole for the time lag (only $1.2 \%$ of a respiratory cycle). As a result, the relative locations of detection signals that occurred would have been unchanged.

The second finding was that flavor detection signals occurred more during the JC than the JO phase (Figure 4(a)), although the average time of the JC phase was shorter than that of the JO (Figure 4(b)). A previous study suggests that mouth movement during chewing can enhance flavor perception through the retronasal route [5]. The participants in this study were estimated the perceived magnitude of two extract solutions (orange and rum) in the mouth with closed and open nostrils. The participants were also estimated the perceived magnitude with or without chewing-like mouth movements, whereas the nostrils were open [5]. This study reveals the active role played by mouth movement in perceiving flavors. Although experimental conditions differ significantly between previous [5] and present studies, the present result (Figure 4) is consistent with previous findings on the active role of mouth movement. However, the present result was not statistically significant $(P=0.281)$. Therefore, the role of mouth movement, that is, jaw-closing, only has a restrictive influence on flavor detection.

The largest limitation of the present study is that the test foods used have fixed concentrations of flavors which may affect the results. Moreover, examining a "concentration" effect is a key point in advancing this research. For the examination, it is necessary to develop test foods that include different concentrations of flavors and similar mechanical properties of test foods, especially hardness. Conversely, this study used three fruit flavors to examine differential effects on respiratory and masticatory phases. The fruit flavors showed similar results, suggesting that food flavors did not affect the phase-dependency revealed in this study.

\section{Acknowledgements}

The authors thank the participants for their cooperation to this study. The au- 
thors also thank Enago (www.enago.jp) for the English language review. This study was partly supported by Grants-in-Aid for Scientific Research from the Ministry of Education, Science and Culture of Japan (No. 26350106 to SM and No. 16K00830 to YM).

\section{References}

[1] Chaput, M.A. (1986) Respiratory-Phase-Related Coding of Olfactory Information in the Olfactory Bulb of Awake Freely-Breathing Rabbits. Physiology \& Behavior, 36, 319-324. https://doi.org/10.1016/0031-9384(86)90023-5

[2] Rawson, N.E. (2000) Human Olfaction. In: Silver, W.L., Restrepo, D. and Finger, T.E., Eds., The Neurobilology of Taste and Smell, Wiley, New York, 257-284.

[3] Haahr, A.M., Bardow, A., Thomsen, C.E., Jensen, S.B., Nauntofte, B., Bakke, M., Adler-Nissen, J. and Bredie, W.L. (2004) Release of Peppermint Flavour Compounds from Chewing Gum: Effect of Oral Functions. Physiology \& Behavior, 82, 531-540. https://doi.org/10.1016/j.physbeh.2004.04.061

[4] Phillips, M.E., Sachdev, R.N., Willhite, D.C. and Shepherd, G.M. (2012) Respiration Drives Network Activity and Modulates Synaptic and Circuit Processing of Lateral Inhibition in the Olfactory Bulb. Journal of Neuroscience, 32, 85-98. https://doi.org/10.1523/JNEUROSCI.4278-11.2012

[5] Burdach, K.J. and Doty, R.L. (1987) The Effects of Mouth Movements, Swallowing, and Spitting on Retronasal Odor Perception. Physiology \& Behavior, 41, 353-356. https://doi.org/10.1016/0031-9384(87)90400-8

[6] Pionnier, E., Chabanet, C., Mioche, L., Le Quere, J.L. and Salles, C. (2004) 1. In Vivo Aroma Release during Eating of a Model Cheese: Relationships with Oral Parameters. Journal of Agriculture and Food Chemistry, 52, 557-564. https://doi.org/10.1021/jf030544v

[7] Miyaoka, S. and Miyaoka, Y. (2013) An Electromyography-Based System for Measuring the Flavor Detection Time in Healthy Adults. Journal of Behavioral and Brain Science, 3, 581-583. https://doi.org/10.4236/jbbs.2013.38061

[8] Miyaoka, S., Yamazaki, T., Ito, N. and Miyaoka, Y. (2014) Factors Determining the Detection Time to Flavor in Healthy Adults. Journal of Behavioral and Brain Sciences, 4, 114-119. https://doi.org/10.4236/jbbs.2014.43015

[9] Rubin, J.E., Shevtsova, N.A., Ermentrout, G.B., Smith, J.C. and Rybak, I.A. (2009) Multiple Rhythmic States in a Model of the Respiratory Central Pattern Generator. Journal of Neurophysiology, 101, 2146-2165. https://doi.org/10.1152/jn.90958.2008

[10] Yamada, Y., Yamamura, K. and Inoue, M. (2005) Coordination of Cranial Motoneurons during Mastication. Respiratory Physiology \& Neurobiology, 147, 177-189. https://doi.org/10.1016/j.resp.2005.02.017

[11] Murphy, C. and Cain, W.S. (1980) Taste and Olfaction: Independence vs. Interaction. Physiology \& Behavior, 24, 601-605. https://doi.org/10.1016/0031-9384(80)90257-7

[12] Murphy, C., Cain, W.S. and Bartoshuk, L.M. (1977) Mutual Action of Taste and Olfaction. Sensory Processes, 1, 204-211.

[13] Troni, W., Melillo, F., Bertolotto, A., Malucchi, S., Capobianco, M., Sperli, F. and Di Sapio, A. (2016) Normative Values for Intertrial Variability of Motor Responses to Nerve Root and Transcranial Stimulation: A Condition for Follow-Up Studies in Individual Subjects. PLOS ONE, 11, e0155268. https://doi.org/10.1371/journal.pone.0155268 
Submit or recommend next manuscript to SCIRP and we will provide best service for you:

Accepting pre-submission inquiries through Email, Facebook, LinkedIn, Twitter, etc. A wide selection of journals (inclusive of 9 subjects, more than 200 journals)

Providing 24-hour high-quality service

User-friendly online submission system

Fair and swift peer-review system

Efficient typesetting and proofreading procedure

Display of the result of downloads and visits, as well as the number of cited articles Maximum dissemination of your research work

Submit your manuscript at: http://papersubmission.scirp.org/

Or contact jbbs@scirp.org 